\title{
IAMJ
}

INTERNATIONAL

AYURVEDIC

MEDICAL JOURNAL

ISSN: 2320-5091

Impact Factor: 6.719

\section{OBSERVATIONAL CASE STUDIES OF GANGAJAL THERAPY}

\section{Vandana Basant Bagdi ${ }^{1}$, Sunita Sunil Niwani ${ }^{2}$, Bharat Jhunjhunwala ${ }^{3}$}

${ }^{1}$ MBBS, MD, DGO, Gynecologist, Consultant Sonologist and Fetal Medicine Specialist, "Suraj” Multispecialty Hospital, Akola, Maharashtra, India

${ }^{2}$ MD Ayurved, Ayurved consultant, Shriniwas Panchkarma Center, Akola, Maharashtra, India

${ }^{3} \mathrm{PhD}$ (Economics), Former Faculty, Indian Institute of Management, Bengaluru, Karnataka, India

Corresponding Author: bharatji@gmail.com

https://doi.org/10.46607/iamj3109052021

(Published Online: May 2021)

Open Access

(C) International Ayurvedic Medical Journal, India 2021

Article Received: 08/04/2021 - Peer Reviewed: 05/05/2021 - Accepted for Publication: 15/05/2021

Check for updates

\begin{abstract}
Vagbhat tells of beneficial properties of Gangajal. A number of recent studies have confirmed these special qualities of Ganga waters. We administered Gangajal to patients suffering from chronic upper- and lower respiratory tract infections and gastro-intestinal problems. Gangajal was collected from upper stretches of the Ganga. Before administration, it was ensured that there was no bacterial or fungal contamination or turbidity in the water and that it was it was crystal clear with small amounts of sediments of the Ganga settled at the bottom. These sediments are supposed to contain large number of phages. The patient was asked not to remove the sediments. Gangajal was given three times a day $-5 \mathrm{ml}$ in morning and evening by nasal route through nebulizer and $10 \mathrm{ml}$ orally in the afternoon to the patients. Patients were advised not to take any hot beverages within one hour of taking Gangajal. Regarding upper- and lower respiratory tracts, nose and nasal passages, patients got 70 percent relief from Gangajal. There is a strong likelihood that phages in-, or other qualities of Gangajal have anti-inflammatory (reduction in nasal mucosal edema) and antiallergic properties that helped beget relief to these patients suffering from chronic ailments. Regarding gastro-intestinal diseases patients got partial relief. More elaborate and long studies are required for further confirmation of all above findings. If those are successful, we can consider Gangajal as an effective, natural, and cost-effective alternative form of therapy which is abundantly available.
\end{abstract}


Keywords: Ganga, phages, Upper respiratory tract, gastro-intestinal, joint pain.

\section{INTRODUCTION}

Vagbhat says: "Water of Ganga is enlivening, satiating, good for heart, calming, stimulates intellect, clean, of imperceptible taste, cold, light and similar to nectar" 1 A number of recent studies have confirmed these special qualities of Ganga waters. In 1896 British physician E. Hanbury Hankin published data about properties of Gangajal in French journal Annels de Institute Pasteur. He added cholera bacteria - Bacterium Vibrio Cholerae - to normal water and to Gangajal. He found that this bacterium did not survive in Gangajal for more than 3 hours while it was found alive for more than 48 hours in normal water. ${ }^{2,3}$ Another British doctor C. E. Nelson found that water taken from a dirty place in the Hooghly did not go stale during his travel to England. Malaria research New Delhi has found out that mosquitoes breeding does not occur in Gangajal. ${ }^{4}$

In a 2008 study, Graham Colm found that boiled Gangajal lost its antibacterial properties, while sieved Gangajal maintained its antibacterial properties. These studies suggest that Ganga absorbs special minerals and vegetations during its flow leading to the development of bacteriophages which have antibacterial properties. Phages uses bacterium machinery and energy to produce more phages until bacterium is destroyed and a greater number of phages are released to invade bacteria in the surrounding area. ${ }^{5}$

Another recent research conducted by Malaria Research Center, New Delhi, shows that mosquito breeding did not occur in the upper stretches of River Ganga and also in waters to which Ganga water was added. Bacteriophages, phytochemicals, metals and biodegradation by other microbes together keep the water clean and pure. ${ }^{6}$

Dr. D. S. Bhargava, Environmental Engineer and Professor of Hydrology found that "immediately after the sewage outfalls into the Ganga, the rate of BOD [biological oxygen demand] removal was very fast in the beginning presumably due to faster coagulation taking place at the sewage outfall points." $7,8,9$

Bacteriophage is widely studied as part of phage therapy for treating bacterial diseases in plants, animals and humans. Bacteriophages in a single environmental source are present in high diversity and can infect different bacteria to different extent, and at different temperatures. Some are resistant to high temperatures and infect pathogenic strains of bacteria and can be used in phage therapy. The complete genome sequences of bacteriophages have also been analyzed from a single environmental source. ${ }^{10}$ These studies give us the encouragement to study the curative properties of Gangajal.

Objective of study: To explore the curative and immunological potential of naturally occurring phages in Gangajal.

Aim of study: To understand symptom-wise benefit of Gangajal.

\section{Material and Methods}

We are presenting case studies of randomly selected patients of different symptoms to whom Gangajal was given three times a day $-5 \mathrm{ml}$ in morning and evening by nasal route through nebulizer and $10 \mathrm{ml}$ orally in the afternoon. Patients were advised not to take any hot beverages within one hour of taking Gangajal. Period of administration of Gangajal was 2 months between December 2020 and February 2021.

The nebulizers were provided to patients by us. There was no control group. Patient's earlier symptoms and benefit after Gangajal therapy were assessed. The patients were administered Gangajal along with prescribed allopathic, ayurvedic and homeopathy medicines that they were taking previously so as to make the cohort study revealing only effects of Gangajal and not the other medicines. We already know the effects of other medicines as they were being taken previously and were continued during the Gangajal therapy. The patients were closely monitored every week and the outcome was recorded.

Out of eight patients, five took Gangajal as per directions as mentioned above. Three patients were irregular in the therapy.

Gangajal was collected from upper stretches of the Ganga and sent to us by courier by Ganga Today Trust 
in well-sealed plastic containers. Before administration, it was ensured that there was no bacterial or fungal contamination or turbidity in the water and that it was it was crystal clear with small amounts of sediments of the Ganga at the bottom. These sediments are supposed to contain large number of phages. The patient was asked not to remove the sediments.

This study recorded both the patient's own assessment as well as that of the medical practitioner.

\section{Results}

Patient No 1: Female, Age 72 years, Weight $70 \mathrm{~kg}$, Prakruti kafa-pitta. Physical Examination: General condition-fair, Pulse 74 b/min, BP 140/80, controlled by T. Etan $5 \mathrm{mg}$ OD. Complaint: 1) BP controlled by medicines; 2) allergic rhinitis 2 years; 3 ) dry cough 6 months; 4) breathlessness 3 years; 5) chest pain while coughing 3 years; 6) joint stiffness and knee joint pain; 7) constipation. Medication: Syrup Kanakasav $15 \mathrm{ml}$ TDS, Sitopaladi Churan 1 TSP BD with honey, T. Deriphyllin afternoon. Doctors' Assessment after Gangajal Therapy: 1) BP controlled by medicines; 2) Allergic rhinitis: nasal catarrh and redness reduced by $70 \%$; 3) dry cough: relieved, frequency reduced, to about 3 times in daytime (earlier 25-30 times) and 6 times in nighttime (earlier 15 times) possibly due to liquefaction of sputum and expectorant formation due to phages in Gangajal; 4) breathlessness: pt. has less difficulty in breathing probably due to expectorant formation which appears to have reduced bronchial spasm Initially on auscultation there were few rhonchi heard. After Gangajal therapy only occasional rhonchi heard; 5) chest pain reduced on palpation; 6) joint stiffness same as before. Knee joint pain and tenderness on knee joint same as before. Patient's Assessment after Gangajal Therapy: 1) BP controlled by medicines; 2) allergic rhinitis shows $70 \%$ improvement; 3 ) dry cough: there is expectorant formation due to Gangajal, $70 \%$ relief. 4) breathlessness: pt. shows $60 \%$ relief. 5) joint stiffness: "I feel more comfortable now after Gangajal Therapy. Previously, I was not comfortable in applying Gangajal due to pain at knee joint; 6) constipation: "I am able to evacuate completely, I don't feel constipated now."
Patient No 2. Female Age 58 years Weight $68 \mathrm{~kg}$. Prakruti pitta. Physical Examination: General condition fair, pulse $76 \mathrm{~b} / \mathrm{min}$, BP 130/80mm hg, menopausal. Complaints: 1) BP controlled to $130 / 80 \mathrm{~m} \mathrm{hg}$ after Tab neuril 5mg-OD; 2) Asthma 7 years; 3) cough and cold 3 years; 4) loss of appetite $3 \mathrm{mts}$; 5) sleeplessness $6 \mathrm{mts}$; 6) joint pain $6 \mathrm{mts}$; knee joint replacement done two years ago. Medication: Pt. on Homeopathy medicine - nature of the medicine not known. Pt. takes tab Deriphyllin as and when required. Doctors' Assessment after Gangajal therapy: 2-3) asthma, cough and cold: initially on chest auscultation there were few rhonchi heard. Only occasional rhonchi heard now possibly following liquefaction of sputum and creating expectorant due to phages in Gangajal; 4) appetite: there was $2 \mathrm{~kg}$ Weight gain-from 66 to $68 \mathrm{~kg}$ suggesting improvement in appetite; 5) sleeplessness: Pt. looked fresh following good sleep; 6) joint pain: no improvement in tenderness found in joint pain or palpation on knee joint. Patient's Assessment after Gangajal Therapy: "My asthma and cough cold show good-about $60 \%$--improvement. I used to get acute asthmatic attack in a span of 15 days which did not recur. Getting good sleep now. Appetite has improved. Low back pain better. Constipation relieved $60 \%$. There is no relief in joint pain and burning sensation."

Patient No 3. Male, Age 80 years, Weight $67 \mathrm{~kg}$., Prakruti pitta-kaf. Physical Examination: General condition good. Pulse $78 \mathrm{~b} / \mathrm{min}$. BP 130/80mm hg controlled by tab olmesar $10 \mathrm{mg}$. Complaint: 1) asthma 2 years; 2) cough, cold and allergic rhinitis $6 \mathrm{mts} ; 3$ ) breathlessness $3 \mathrm{mts}$; 4) insomnia $6 \mathrm{mts}$; 5) acidity $1 \mathrm{yr}$; 6 ) frequent passing of urine and burning 2 years, operated for kidney stone 15 years ago; 7) joint pain $1 \mathrm{yr}$. Medication: Tab Allegra 1 OD for cough and cold SOS. Tab olmesar $10 \mathrm{mg}$ for BP. Tab Deriphyllin SOS. Doctors' Assessment after Gangajal Therapy: 1) asthma: difficulty in breathing relieved by $60 \%$. There were few rhonchi on chest auscultation before Gangajal therapy, only occasional rhonchi after therapy suggesting improvement in bronchial spasm. 2) breathlessness: frequency reduced from about 10 bouts a day and 10 bouts in night to about 3-4 bouts in day and 4-5 bouts in night. 3) No change in insomnia, acidity, urinary 
problems and joint pain. Patient's Assessment after Gangajal Therapy: "I got relief from acute asthmatic attacks which happened at duration of 8-10 days. I am also relieved of irritating dry cough with reduction in frequency. I have no relief in acidity, frequency of urine and joint pain."

Patient No 4. Female, Age 45 years, Weight $70 \mathrm{~kg}$, Prakruti kaph-pitta. Physical Examination: General condition fair. Pulse $74 \mathrm{~b} / \mathrm{min}$. BP 130/80mm hg controlled by Tab Aten $5 \mathrm{mg}$ OD. Complaint: 1) asthma 12 years; 2) allergic rhinitis, sneezing, cough and cold 1 month; 3) joint pain specially knee and ankle joints 5 years; 4) hypertension controlled by medicine 3 years. Medication: Tab Aten $5 \mathrm{mg}$ OD. Tab Deriphyllin SOS. Taking homeopathy medicines for bronchitis but nature of medicine not known. Doctors' Assessment after Gangajal Therapy: 1) asthma: difficulty in breathing, cough and cold relieved by $30-40 \%$ possibly following cough liquefaction of sputum by phages in Gangajal. 2) allergic rhinitis persists. 3) no relief in knee joint pain and ankle joint tender on palpation. Patient's Assessment after Gangajal Therapy: "I have $30-40 \%$ relief in asthma and cough cold. I have no relief in joint pain."

Patient No 5. Female, Age 61 years. Weight $68 \mathrm{~kg}$, Prakruti pitta-vata. Physical Examination: General condition fair. Pulse 76 b/min. BP 130/90mm hg. Complaint: 1) knee, ankle and shoulder joint pain, stiffness and numbness 5 years; 2) lower back pain 4 years; 3) insomnia 6 months. Medication: Dashmoolarishta 15 $\mathrm{ml}$ BD. Tab Yograj guggul 2 BD. Tab Arogyavardhini 2 BD. Doctors' Assessment after Gangajal Therapy: 1) knee, ankle and shoulder joint seen to be less tender than earlier, stiffness appears slightly less than before and touch sensation appears to have improved. 2-3) No improvement in back pain and insomnia. Patient's Assessment after Gangajal Therapy: There is 30\% improvement in my joint pain stiffness, and numbness slightly reduced. No improvement in lower backache and sleep disturbance.

\section{DISCUSSION}

First, regarding upper respiratory tract- nose and nasal passages. There were symptoms of chronic allergic rhinitis in patient numbers 1,3 , and 4 . Normally they are treated by medications as outlined above. These medications did not beget relief to the patients, and they were suffering from chronic ailments. They got 70 percent relief from Upper Respiratory Tract infections from Gangajal. There is a strong likelihood that phages in-, or other qualities of Gangajal have anti-inflammatory (reduction in nasal mucosal edema) and antiallergic properties that helped beget relief to these patients suffering from chronic ailments.

Second, regarding lower respiratory tract-Trachea, bronchial tree and alveoli. The patients had symptoms like breathlessness, chronic cough and cold and asthma. In our study, use of Gangajal by nebulizer and oral route showed 30 to $60 \%$ reduction in symptoms and Rhonchi (on auscultation) suggesting that phages have anti-inflammatory properties and they help in liquefaction of thick mucus.

Three, regarding gastro-intestinal diseases, patient No 1 had improvement in appetite, patient No 2 had relief from constipation and patient No 3 showed no improvement in acidity. We can assume that constipation and appetite are multifactorial, and relief could be due to change in gastro-intestinal flora. The sample size is small to be able to comment on the effect of Gangajal on acidity since it is unclear whether acids in stomach are affected by Gangajal.

Four, regarding joint pains, patient no 5 showed slight (30\%) symptomatic improvement relief in joint stiffness, pain and touch sensation. And these, in our opinion cannot be attributed to Gangajal alone. This requires more study.

Relief of insomnia was noted in two patients.

We cannot rule out the role pf psychology in these patients as Gangajal is considered holy water and positive beliefs are associated with it.

More elaborate and long studies are required for further confirmation of all above findings. If those are successful, we can consider Gangajal as an effective, natural, and cost-effective alternative form of therapy which is abundantly available. 


\section{CONCLUSION}

Gangajal Therapy holds good potential for upper- and lower respiratory tract infections. Topical application can be tried for joint pain. Gangajal can provide us with an effective, natural, and cost-effective alternative form of therapy.

Financial support: Nil. Administrative support was provided by Ganga Today Trust.

Patient consent was obtained however names are not disclosed.

\section{REFERENCES}

1. Vagbhat, Ashtanga Hridaya Sutra Sthan, 5:1-2.

2. Hankin, E. (1896). L'action Bactericide des eaux la Jumna et du Ganga sur le vibrion du cholera. Ann Inst Pasteur, 511-523.

3. Abedon et al., S. (2011). Bacteriophage prehistory: Is or is not Hankin, 1896, a phage reference? Bacteriophage, 1(3), 174-178.

4. Shukla, A., \& Vandana, A. (1995). Ganga: A Water Marvel. New Delhi: S. B. Nangia.

5. Somani, Hari Prasad, Dharma aur Vigyan, Prabhat Prakashan, Delhi, 2018, Page 157-163.

6. Keary R. et.al (2013), Bacteriophages and their endolysins for control of pathogenic bacteria. Science, technology and education (A. Mendez- Vilas, Ed.).

7. Bhargava, D. S., "Coagulating Capacity of Ganga at Kanpur," Food Industries and the Environment, Int. Symp., Budapest, Hungary 1982, Page 140.

8. Bhargava, D. (1983). Most rapid BOD assimilation in Ganga and Yamuna rivers. Journal of Environmental Engineering, 109(1), 174-188.

9. Bhargava, D. (1987). Nature and the Ganga. Environmental Conservation 14 (04), 307-318.

10. Wittebole et al., X. (2014). A historical overview of bacteriophages therapy as an alternative to antibiotics for the treatment of bacterial pathogens. Landes Bioscience Virulence, 226-235.

\section{Source of Support: Nil \\ Conflict of Interest: None Declared}

How to cite this URL: Vandana Basant Bagdi et al: Observational Case Studies of Gangajal Therapy. International Ayurvedic Medical Journal \{online\} 2021 \{cited May, 2021\} Available from: http://www.iamj.in/posts/images/upload/1126_1130.pdf 